\title{
Instituições e sociabilidades: estratégias para a cidadania no oitocentos do Vale Do Paraíba Fluminense
}

\section{Institutions and sociabilities: strategies for citizenship in the eighties in the Paraíba Valley Of Rio De Janeiro}

DOI: $10.46814 /$ lajdv3n3-017

Recebimento dos originais: 01/05/2021

Aceitação para publicação: 30/06/2021

\author{
Raimundo César de Oliveira Mattos \\ Doutor em História pela UERJ. Professor Titular do Centro de Ensino Superior de Valença - \\ UNIFAA. \\ ENDEREÇO: Rua Domingos Cosati, 485 - Centro - Valença - RJ. \\ E-mail: raimundomattos@bol.com.br
}

\section{RESUMO}

A obtenção da cidadania no século XIX era um alvo perseguido por não poucos. Em um país que limitava esse direito a poucos elementos, estrangeiros e elementos que não possuíam um "nome de família" valiam-se de uma série de estratégias para alcançarem uma posição relevante no aristocrático Vale do Paraíba Fluminense. No entanto, também aqueles membros da "boa sociedade" procuravam criar e manter sua imagem diante de todos. Assim sendo, lançavam mão de instituições filantrópicas, religiosas, políticas e outras para se destacarem. Em Valença, situada na província fluminense, encontram-se alguns dos mais destacados exemplos disso, como o Conde de Baependy, criador e primeiro provedor da Irmandade da Santa Casa de Misericórdia, o Visconde do Rio Preto e o Comendador Manoel Antônio Esteves. Esse trabalho procurar demonstrar como agiram esses elementos, em demanda da inserção social, da cidadania e da construção da auto-imagem.

Palavras-chave: Sociabilidades. Boa Sociedade. Instituições.

\begin{abstract}
The acquisition of citizenship in the nineteenth century was the object of more than a few. In a country that limited this right to a few people, foreigners and those who didn't have a "family name" made use of a series of strategies to reach a relevant position in the aristocratic Paraiba Valley in Rio de Janeiro State. However, those members of the "good society" also tried to create and maintain a good image before everyone. Thus, they made use of philanthropic, religious, and political institutions among others to stand out. In Valença, located in the fluminense province, we can find some of the most outstanding examples of this fact, such as the Count of Baependy, founder and first provider of the Irmandade da Santa Casa de Misericordia de Valença, the Viscount of Rio Preto and the Commendator Manoel Antonio Esteves. This paper aims at demonstrating how these elements acted in search of social inclusion, citizenship and the construction of self-image.
\end{abstract}

Keywords: Sociabilities. Good Society. Institutions. 


\section{INTRODUÇÃO}

O Vale do Paraíba Fluminense é conhecido, em especial, pelo prestígio que alcançou com a produção cafeeira no século XIX. Ainda hoje podem-se encontrar vestígios dessa opulência nas antigas fazendas e casarões que marcaram toda uma época. O poderio dos barões do café cresceu e expandiuse muito rapidamente, assim como a sua decadência provocada por diversos fatores. No entanto, esses barões não viviam mergulhados em uma espécie de apatia social, dependendo unicamente do café. Ao contrário, articulavam-se, trabalhavam arduamente nas cidades e vilas e também junto à Corte do Rio de Janeiro, pessoalmente ou através de seus representantes, os comissários de café que exerciam muito mais do que uma simples função de intermediários na compra e venda a produção.

Várias famílias formaram o seu poderio econômico mas não se aquietavam com isso e também desejavam prestígio social e político, visando o reconhecimento de seus pares e da sociedade em que viviam. A busca pela formação de uma imagem, e mesmo de uma autoimagem era constante em suas vidas. Assim, traçavam estratégicas de sociabilidade e cidadania, lançando mão de estratégias diversas como a participação na vida política através da filiação partidária e consequente disputa pela vereança, em irmandades religiosas, nos tribunais do júri, na filantropia e na busca por um tão sonhado título nobiliárquico, que vinha coroar todo o esforço empreendido o que, no entanto, não encerrava os seus esforços no sentido de aumentarem o prestígio e se destacarem no meio social.

Entre tantas outras, duas cidades assomam como palco para a articulação de uma série de estratégias: Vassouras e Valença. Famílias poderosas organizavam estratégias constantes para alcançarem os seus objetivos, como os Teixeira Leite e os Correia e Castro na primeira e os Nogueira da Gama na segunda que, entretanto, possuiu mais indivíduos no cenário oitocentista, diferenciandose de Vassouras que concentrava a ação em suas famílias como as citadas. Em Valença, por sua vez, encontramos personalidades como o Visconde do Rio Preto e o Comendador Manoel Antônio Esteves que, agindo da mesma forma, não projetaram o nome de suas respectivas famílias, mas apenas o seu próprio. A respeito dessa cidade e de seus principais barões do café trataremos adiante.

\section{OBJETIVOS}

Procuramos aqui demonstrar como os barões de café no Vale do Paraíba Fluminense, em especial na cidade de Valença, articulavam-se entre si na formação de uma rede de sociabilidades e traçavam estratégias de cidadania procurando prestígio e a formação de uma imagem e mesmo de uma autoimagem que perpetuasse o seu nome na sociedade.

Além disso, iremos demonstrar como as instituições, políticas em especial, eram utilizadas para a obtenção dos intentos dos cafeicultores na elaboração de uma intrincada malha de sociabilidades em que cada um tinha um papel a cumprir na sociedade oitocentista que se firmava pelo poder do café. 
3 O CAFÉ NO VALE dO PARAÍbA FLUMINENSE E A INSTALAÇÃo DA "BOA SOCIEDADE" OITOCENTISTA

O café chegou à região do Vale do Paraíba Fluminense ainda no período joanino. A Estrada do Comércio servia à área onde a rubiácea começa a se impor.2 O aumento do cultivo processou-se rapidamente, atingindo São João Marcos e Campo Alegre e, a partir daí, estendeu-se para o vale. Os recursos e os caminhos das tropas que abasteciam a região tiveram um lugar de destaque na expansão da economia cafeeira, sendo que por essas vias de penetração é que foram se estabelecendo sítios e pousos de tropeiros que forneciam à Capital gêneros agrícolas e alguns engenhos produtores de açúcar, além dos primeiros cafezais. No I Reinado expandem-se as lavouras e, já em 1835, contavam-se em Valença e Vassouras fazendas de 500 mil e 800 mil cafeeiros.3

A produção cafeeira no vale alcançou o seu ápice nas décadas de 1850 e 1860, quando são organizadas e melhor articuladas as redes de sociabilidade e de poder. Assim:

O apogeu (do café) se deu entre 1851 e 1865, ainda que o ritmo da produção começasse a diminuir, premido pela escassez de braços e de terras virgens para alimentar a expansão experimentada no período anterior. (...) Construíram-se luxuosas casas de morada como sede das fazendas e símbolos de ostentação e riqueza. (...) Estreitaram-se as relações entre os grandes proprietários e a Corte. Adquiriram-se os almejados títulos de nobreza em maior escala. O patriarcalismo e o paternalismo, nas novas condições demográficas e sociais resultantes da extinção do tráfico internacional de cativos, pareciam, então, estar perto de moldar uma comunidade escrava mais estável (...).4

Segundo Ilmar Mattos, os cafeicultores fluminenses foram responsáveis por consolidar a Monarquia, obtendo êxito em unir as suas vidas aos destinos de pessoas que, em especial na Província do Rio de Janeiro, assistiam uma mudança em suas existências à medida que substituíam as tradicionais culturas de milho, feijão e cana de açúcar por cafeeiros. Eram proprietários que, dependendo cada vez de uma maior quantidade de terra e de mais trabalhadores escravos, passavam a depender também do Estado, no qual predominavam os "saquaremas", defensores intransigentes da estrutura colonial de produção.5 A opinião do papel das elites provincianas na formação e consolidação do Estado imperial brasileiro também é compartilhada por Maria Fernanda Martins, apontando para um interesse recíproco, citando Henshall6, pelo qual, seguindo o exemplo europeu, havia uma necessidade de a monarquia negociar e lidar com as elites e estas, uma necessidade de se manterem próximas ao Estado que se formava.

Em meados do século XIX, a produção cafeeira do Vale do Paraíba bate recorde. É o apogeu da cultura cafeeira. Valença goza, já por essa época, de grande prestígio econômico. O crescimento da cidade, elevada a essa condição em 1857 pela lei número 961 de 29 de setembro e da produção cafeeira, tornaram necessária a criação da ferrovia. Após pouco mais de dois anos de obras foi inaugurada a 
Estrada de Ferro União Valenciana, a 18 de maio de 1871, com a presença do imperador e comitiva, ampliando-se, com o tempo, a malha ferroviária até cidades vizinhas. Por volta de 1859 a cidade tinha cerca de 5.000 habitantes na sua sede e todo o município tinha 40.000 habitantes, entre homens livres e escravos. A necessidade de mão de obra para as plantações de café fez com que o município tivesse uma das maiores populações negras da então província do Rio de Janeiro, senão do Brasil. Em 1888 ainda trabalhavam na lavoura de café cerca de 25.000 escravos. A partir de 1860, obras como ajardinamento, calçamento, instalação de iluminação pública, água encanada, novas denominações às ruas e a construção de um teatro, são realizadas na cidade. O papel da elite local é de extrema importância para se compreender a cultura política instalada na região. Já a origem dos sesmeiros que se estabeleceram aí denota o que se organizará no decorrer do século XIX: a formação de famílias que, vindo principalmente de Minas Gerais, se transformam aos poucos na boa sociedade local. Falando a respeito da origem desses sesmeiros, explica Vitor Nunes:

Primeiramente foi possível notar que na sua maioria eram oriundos da Capitania das Minas
Gerais, principalmente da Zona da Mata mineira e, em especial da Comarca do Rio das Mortes.
Estas famílias eram: Almeida e Gama, Carneiro Leão, que na região de Valença deu origem
aos Carneiro Nogueira da Costa e Gama, Ferreira Leite, Fortes, Fortes de Bustamante, Leite
Guimarães, Monteiro de Barros, Nogueira de Abreu e Mello, Nogueira da Gama, Souza Lima,
Souza Rezende, Souza Werneck (que no Vale do Paraíba Fluminense dará origem a vários clãs
como os Chagas Werneck, Lacerda Werneck e Santos Werneck), Tostes, Valle Amado, entre
outras. Foram também sesmeiros do Vale do Rio Preto e Paraíba do Sul famílias como Araújo
Roxo, Martins, Pereira de Mesquita, Pereira de Faro, Pimentel, Rodrigues Paes Leme, entre
outras.7

Essas famílias se lançam na política, na formação de alianças e de redes de sociabilidade que, com objetivos bem definidos, acabam organizando lideranças capazes de levar adiante os seus propósitos. A Câmara Municipal era um local privilegiado no jogo do poder e para a formação e manutenção de alianças. Ainda que impossibilitada de legislar sobre vários temas, a municipalidade faz-se valer de várias estratégias de sociabilidade. A Câmara de Valença já surge em um contexto de poderes restritos, em decorrência da diminuição das prerrogativas dos vereadores ocorrida no I Reinado; entretanto, por esse mesmo motivo, não há nenhum motivo de insatisfação por parte dos poderes locais. Seus interesses são agora adquiridos mediante a formação de redes de sociabilidade. Em se tratando de Valença, podemos dividir a evolução da Câmara Municipal em períodos bem definidos.

\section{A EVOLUÇÃO DA CÂMARA MUNICIPAL DE VALENÇA}

Os períodos aqui apontados na evolução da Câmara em Valença surgem de uma constatação diante da forte influência de dois políticos locais: Brás Carneiro Nogueira da Gama, o Conde de 
Baependy, e Domingos Custódio Guimarães, o Visconde do Rio Preto. O período de estruturação do legislativo valenciano fica estabelecido entre 1826 e 1832, caracterizado por ser um período de organização e ajustes. A primeira eleição para a Câmara só aconteceu em 1828, com a eleição do Comendador José da Silveira Vargas para presidente. Essas datas balizam o momento da instalação da Câmara e o fim do mandato da primeira legislatura. Chamamos este período de estruturação por um motivo bem simples: é nesse momento que a Câmara, ainda não possuindo sede própria e todo o aparato público, precisava de uma estruturação e regulamentação. E foi isso que a primeira legislatura fez. $\mathrm{O}$ período Baependy compreende os anos de 1833 e 1860. O Visconde de Baependy foi vereador por quatro legislaturas, sendo presidente em três.

Foi grande a influência que o Conde de Baependy e sua família, os Nogueira da Gama, exerceram na região, a começar pela legislatura de 1833/1836, quando dois outros vereadores são parentes do próprio Baependy, Manoel do Vale Amado e Ignácio José Nogueira da Gama, tio do mesmo, irmão mais novo do Marquês de Baependy, passou a exercer na região. Além desses podemos citar ainda outros personagens como Custódio Ferreira Leite, o Barão de Ayuruoca e Camilo José Pereira Faro, filho do primeiro Barão do Rio Bonito. É preciso salientar que todos esses personagens são fazendeiros. Na legislatura de 1837/1840, outro personagem importante na época que volta à cena é José da Silveira Vargas. Além dele, outros fazendeiros compõem o quadro de vereadores, como João Pinheiro de Souza, pai do futuro Visconde de Ipiabas e Reginaldo de Souza Werneck, oriundo de importante família da região. Mas o que devemos notar ainda é a presença não apenas de fazendeiros, mas também de advogados/capitalistas, como Antônio Carlos Ferreira e João Baptista de Araújo Leite que, ao longo do tempo, tornaram-se importantes articuladores na política local, tanto no período Baependy quanto no período Rio Preto, indo inclusive além desses dois períodos. A presença desses dois personagens já prenuncia o que marca o tom da sociabilidade na região. Era um grupo intermediário e gravitava em torno da classe senhorial. Essa configuração política se mantém por todo o século XIX, quando um grupo depende do outro.

Se analisarmos ainda outra legislatura, como a de 1849/1852, veremos bem as redes de sociabilidade já estabelecidas e a respectiva configuração política. Notamos que o presidente é o mesmo Visconde de Baependy, mas outro fazendeiro surge na política local: Antônio Leite Pinto, sobrinho do Barão de Ayuruoca. O Dr. Francisco Antônio de Souza Nunes que, além de ser fazendeiro, também era médico e, além dele, temos Francisco de Salles Pinheiro de Souza, fazendeiro e irmão de João Pinheiro de Souza. Estes personagens demonstram bem como a política local estava intimamente ligada com a política da região e, consequentemente, com a política nacional, com a presença de famílias importantes como os Pinheiro de Souza, Werneck, Pereira Faro, Leite Pinto, Ferreira Leite e, por fim, os Nogueira da Gama. A continuação teve início com a distribuição das sesmarias. 
Mesmo com a ausência do Conde de Baependy na legislatura de 1857/1860, por ter se lançado na política nacional, a presença de seu irmão, Manoel Jacinto Carneiro Nogueira da Gama, futuro Barão de Juparanã, mantém estes anos no período Baependy. Neste momento os planos da família eram que um representasse os interesses políticos no âmbito local e outro, no nacional. No entanto, a liderança conquistada por Baependy não foi alcançada por seu irmão mais novo, tendo surgido mesmo um grupo de oposição. Dentre os oposicionistas destacava-se a figura de Saldanha Marinho, importante político nacional e advogado que defendeu muitos clientes na região. Pela falta de habilidade de sociabilizarse, além de não despertar muita confiança, Manoel Jacinto acabou levando a região a uma época de dúvidas, ficando a cidade sem um líder capaz como tinha sido seu irmão.

Essa ausência de liderança precisava ser revertida. É aqui que surge a figura de Domingos Custódio Guimarães, na época Barão do Rio Preto e depois Visconde de mesmo título. Já no início da década de 1850, ele começou a comprar propriedades e terrenos no centro da cidade para construir uma residência urbana. Adquiriu algumas propriedades em locais estratégicos, mas optou por construir um palacete em frente à Praça da Câmara. Não poupou e construiu uma suntuosa residência que poderia ser vista por todos. A construção da casa terminou em 1858, ano em que assume o cargo de delegado da Freguesia de Santa Tereza - esta foi a sua primeira atividade de homem público rastreada até o momento. Logo em seguida foi eleito presidente da Câmara para a legislatura de 1861/1864 e reeleito para a legislatura de 1865/1868.

Rogério Tjader, na sua biografia sobre o Visconde do Rio Preto8, descreve a instalação das primeiras fazendas na região de Valença. Ele afirma que, após a chegada da Família Real portuguesa em 1808, “toda a área da margem esquerda do rio Paraíba do Sul, até a margem direita do Rio Preto (...) já se encontrava dividida em sesmarias".9 Com o desaparecimento dos índios, a região se apresentava como ideal para a formação de fazendas, apesar de a tarefa não se apresentar fácil. Ele ainda afirma que o período em que mais foram distribuídas sesmarias mediou entre 1810 e 1819 , perfazendo um total de 149, sendo que a última doada data de 1835. Entre essas sesmarias e fazendas formadas encontram-se aquelas que pertenceram ao principal cafeicultor não só de Valença, mas de toda a região, que foi o Visconde do Rio Preto.

Comerciante originário de Carrancas, em Minas Gerais, Domingos Custódio Guimarães enriqueceu no abastecimento de carne à cidade do Rio de Janeiro e, mais tarde, resolveu estabelecerse mais próximo da Corte, tendo comprado várias fazendas e sesmarias na região de Valença. Uma delas, doada inicialmente em 1810 a João Pedro Maynard d'Affonseca e Sá, localizada no local onde o Rio Preto recebe as águas do Rio das Flores, recebeu o nome de Barra das Flores, mais tarde substituído por Loanda. Outra de mesma data foi a que recebeu o nome de Flores do Paraíso, concedida ao Padre Manoel Joaquim Nunes Cordeiro a qual, no final de 1810, foi negociada com João Pedro 
Maynard, que iniciou a derrubada das matas e construiu as primeiras instalações. Essas duas, mais tarde, passaram a pertencer ao Visconde do Rio Preto, juntamente com várias outras.10

Esse segundo momento é o período que denominamos de Rio Preto porque, assim como Baependy, ele soube se articular até com seus opositores, alçando projetos de grande porte para a região. Para tanto, não mediu esforços na construção da imagem de grande líder, investiu recursos próprios em obras públicas, irmandades e associações, construindo uma ampla rede de subalternos. Rio Preto soube como ninguém administrar a máquina pública como se estivesse administrando sua vida privada. De fato, ele transformou tudo em uma extensão de sua própria casa. Sua forma de gerir os negócios públicos em nada se diferenciou de seus negócios privados. Ao seu lado, algumas famílias voltaram a ser fortes e os projetos da classe senhorial caminhavam bem. Rio Preto era o líder local, Baependy era o Vice-Presidente da Província do Rio de Janeiro e, segundo Maria Fernanda Vieira Martins11, os dois contavam com o apoio do Visconde do Cruzeiro, então membro do Conselho de Estado. Era o sonho da boa sociedade se concretizando. Mas nem tudo poderia dar certo para este grupo e foi quando receberam a notícia do falecimento do Visconde do Rio Preto. Era época de eleição e todos davam como certa a vitória do Visconde. Mas ele morreu repentinamente sem ver a apuração dos votos que lhe garantiriam a reeleição para o terceiro mandato como presidente da Câmara. Sua morte provocou verdadeira comoção, como bem se depreende da notícia publicada no informativo "Alagôas":

\footnotetext{
A imprensa valenciana, como representante das grandes idéias, como admiradora das nobres ações, como defensora dos importantes interesses de seu rico município, faltaria sem dúvida ao mais sagrado dever se não viesse render sua última homenagem a este cidadão benemérito. (...)

Se foram sempre sinceros, e merecidos os louvores que outrora lhe tributávamos por suas nobres ações, é também sincera e desinteressada a oferenda que ora fazemos ao morto. Jamais empunhamos o turíbulo da vil lisonja, jamais queimamos o incenso corrompido da hipocrisia, porque embora obscuros na carreira do jornalismo, sempre soubemos conservar-nos na altura de nossa dignidade12.
}

E, mais para frente:

Veremos agora se aqueles que ambicionaram este lugar que sempre fora brilhantemente ocupado, o imitarão, e o tomarão por modelo. Com a morte do ilustre visconde Valença perdeu seu protetor, seu verdadeiro arrimo. Lamentemos, pois, sua morte como uma perda irreparável. Choremos, valencianos!13

Com a sua morte, abriu-se novamente um vácuo na cidade. Entretanto, o mesmo jornal “Alagôas", já apontava outro personagem capaz de levar adiante o projeto de construção da linha férrea, iniciado por Rio Preto - Manoel Antônio Esteves. A boa sociedade local não podia abrir mão de um líder e, por isso, o jornal de linha conservadora comunicava: 
(...) e nem o importantíssimo projeto do ramal morrerá sufocado pelo asfixiante hálito do desânimo, por que consta-nos que o prestimoso cidadão e importante fazendeiro do município o Sr. Manoel Antonio (sic) Esteves, tomara a peito tornar efetiva sua realização. Vouloir c'est pouvoir. Oxalá o Sr. Esteves queira, cremos que neste caso sua vontade -será hercúlea clava capaz de esmagar a hidra multicápite das impossibilidades e dificuldades. O Sr. Esteves por este fato torna-se credor dos nossos mais sinceros encômios, e da gratidão dos Valencianos.

\section{MANOEL ANTÔNIO ESTEVES E ESTRATÉGIAS DE CIDADANIA E SOCIABILIDADE}

Manoel Antônio Esteves, português de nascimento, naturalizado brasileiro, na opinião do Alagôas, passaria a ser esse novo líder capaz de, se não levar adiante todos os projetos do Visconde do Rio Preto ou defender os interesses gerais da "boa sociedade", pelo menos liderar a região em busca de objetivos que garantiriam a manutenção do poder da classe senhorial no local que se apresentava como de tão grande importância durante o II Reinado. Entretanto ele, ao contrário do Visconde de Baependy e do Visconde do Rio Preto, grandes líderes locais que se sucederam à frente desta "boa sociedade", ele não tinha ligações políticas partidárias nem se lançou na vida política a partir daí. É apresentado pelo jornal como alguém capaz de levar adiante a construção da linha férrea preenchendo, assim, um vazio surgido na região com a morte de Domingos Custódio Guimarães. O proprietário do “Alagôas", também de origem portuguesa, parece alçá-lo a uma condição de liderança e conclama, mais adiante, os fazendeiros a que se unam a Manoel Esteves na tarefa de efetivação da ferrovia.

De fato, ele não apenas conseguiu a construção da Estrada de Ferro União Valenciana, como obteve que uma de suas estações fosse construída na entrada de sua fazenda, o quê facilitou em muito o escoamento da produção cafeeira. Observe-se que ele é chamado de "prestimoso cidadão" pelo jornal, ainda que de origem portuguesa. Mas sua trajetória no Vale do Paraíba Fluminense é ilustrativa da busca pela identidade e pela cidadania.

Ao morrer em 1879, aos 66 anos de idade, deixou onze filhos, sendo oito ainda menores de idade. Foi um indivíduo que se destacou no cenário oitocentista, marcado por estruturas e regras de poder, estratégias de sociabilidade e normas de conduta.

\section{CONSIDERAÇÕES FINAIS}

Como percebemos, as lideranças sociais e políticas locais possuíam um projeto que utilizava uma série de estratégias e alcançava uma diversidade de instituições como a Câmara, os jornais e, caso não raro na história do país, as irmandades e associações de beneficência. Criada, por exemplo, em 1838, pelo mencionado Conde de Baependy, a Irmandade da Santa Casa da Misericórdia de Valença tornou-se um local de referência para essa boa sociedade, tendo sido o próprio Baependy o seu primeiro provedor. Também o Visconde do Rio Preto elegeu-se provedor da Irmandade por várias vezes, assim como Manoel Esteves, este, porém, alguns meses antes de sua morte. Registre-se ainda o fato de que, 
se não era uma regra, pelo menos tornou-se um costume que membros da mesa provedora da Irmandade também exerciam cargos políticos, denotando uma forte ligação entre as instituições que, assim, se afiguram, conforme afirmado, como locais em que a boa sociedade local exercia o seu poder e organizava as suas redes de sociabilidade.

Famílias e indivíduos se articulavam em tais locais buscando manter um prestígio que ia além do fato de serem ricos proprietários de terras e escravos. Eles desejavam mais do que o poderio econômico e faziam o possível para terem seus nomes perpetuados e reconhecidos. Pelo que vimos, lançavam mão de uma série de meios para alcançarem os seus objetivos.

A própria sociedade oitocentista dependia da ação de seus barões, titulados ou não, que se apresentavam como filantropos e garantidores do funcionamento até mesmo de serviços hoje considerados como essenciais. O Visconde do Rio Preto, por exemplo, foi o responsável pela instalação do primeiro sistema de abastecimento de água em Valença e, tanto ele como Manoel Esteves, como provedores da Irmandade da Santa Casa de Misericórdia, fundada pelo Conde de Baependy, assumiram o cargo em épocas de grandes dificuldades enfrentadas pela mesma, sendo responsáveis pelo pagamento de dívidas contraídas por ela e vistos como "salvadores" da instituição. Também na implantação do ramal da linha férrea, visto como indispensável para o escoamento da produção cafeeira, são eles que assumem a liderança do projeto que é descrito pelos jornais como importante não apenas para os cafeicultores, mas para toda a cidade. De fato, Valença dependia disso para enviar o café para os portos de exportação e podemos mesmo dizer que, se “o Império era o vale", o vale era o café.

Em suma, a sociedade cafeicultora do oitocentos se articulava mediante a ação de sua elite agrária que, por sua vez, garantia a manutenção do status quo e traçava meios de angariar prestígio, manter o poder e ser reconhecida por todos. 


\section{REFERENCIAS}

2 Cf. MARTINS, Ana Luíza. História do Café. São Paulo: Contexto, 2008, p. 113.

3 Ibid., p. 74.

4 SALLES, Ricardo. Vassouras -século XIX. Da liberdade de se ter escravos à liberdade como direito. In: CARVALHO, José Murilo de (org.). Nação e Cidadania no Império: novos horizontes. Rio de Janeiro: Civilização Brasileira, 2007, p. 291.

5 Cf. MATTOS, Ilmar Rohloff de.; GONÇALVES, Márcia de Almeida. O Império da boa sociedade. A consolidação do Estado imperial brasileiro. São Paulo: Atual, 2005, p. 48.

6 HENSHALL, Nicholas. "El absolutismo de la edad moderna, 1500-1700. Realidade política ou propaganda?". In: DUCCHARDT, Heinz.; ASCH, Ronald G. (eds.). El Absolutismo, un mito? Revision de um concepto historiográfico clave. Barcelona: Idea Books, 2000. Citado em: MARTINS, Maria Fernanda. Os tempos da mudança: elites, poder e redes familiares no Brasil, séculos XVIII e XIX. In: FRAGOSO, João Luís Ribeiro.; ALMEIDA, Carla Maria Carvalho de.; SAMPAIO, Antonio Carlos Jucá de.. Conquistadores e Negociantes. Histórias de elites no Antigo Regime nos trópicos: América lusa, século XVI a XVIII. Rio de Janeiro: Civilização Brasileira, 2007, p. 422.

7 NUNES, Vitor Nuno Duarte Flecho. Da formação fundiária portuguesa à distribuição de sesmarias no Vale dos Rios Preto e Paraíba do Sul. Trabalho de conclusão de curso apresentado ao CESVA. Valença: s. ed., 2009, pp. 17-18.

8 TJADER, Rogério da Silva. Visconde do Rio Preto -sua vida, sua obra. O Esplendor de Valença. Valença: PC Duboc, 2004.

9 TJADER, Rogério da Silva. Op. Cit., p. 36.

10 Citem-se outras propriedades do Visconde do Rio Preto: as fazendas Criméia, São Leandro, Santa Vitória, Santa Teresa, Santa Bárbara, Aliança, Monte Alverne, Santa Genoveva e Santa Rosa das Flores.

11 MARTINS, Maria Fernanda Vieira. O círculo dos grandes: um estudo sobre política, elites e redes no segundo reinado a partir da trajetória do Visconde do Cruzeiro (1854-1889). Luiz de Fora: Lócus. Revista de História, v. 13, n. 1, pp. 93-122, 2007.

12 In: “O Alagôas”. nº 04,13 de setembro de 1868. CD-009CDH/CESVA.

13 In: “O Alagôas”. Ano I, nº 04, 13 de setembro de 1868.CD-009CDH/CESVA.

14 O Alagôas. Valença, ano I, nº 8, 11 de outubro de 1868. CD-009CDH/CESVA. 